\title{
Hypoalgesic effect of Spirulina platensis on the sciatic neuropathic pain induced by chronic constriction injury in male rats
}

\author{
Hossein Ali Safakhah ${ }^{1,2}{ }^{\oplus}$, Farzaneh Tamimi $^{3}$, Nasroallah Moradi kor ${ }^{1 \oplus}$, Ahmad Reza Bandegi $^{4}$, Ali Ghanbari $^{1, *}$
}

${ }^{1}$ Research Center of physiology, Semnan University of Medical Sciences, Semnan, Iran

${ }^{2}$ Department of physiology, Faculty of Medicine, Semnan University of Medical Sciences, Semnan, Iran

${ }^{3}$ Student Research Committee, Faculty of Medicine, Semnan University of Medical Sciences, Semnan, Iran

${ }^{4}$ Department of Biochemistry, Faculty of Medicine, Semnan University of Medical Sciences, Semnan, Iran

\section{Correspondence}

Ali Ghanbari, Research Center of physiology, Semnan University of Medical Sciences, Semnan, Iran

Email: ghanbari@semums.ac.ir

History

- Received: 27 July 2018

- Accepted: 10 September 2018

- Published: 28 September 2018

DOI :

https://doi.org/10.15419/bmrat.v5i9.477

\section{Check for updates}

\section{Copyright}

(c) Biomedpress. This is an openaccess article distributed under the terms of the Creative Commons Attribution 4.0 International license.

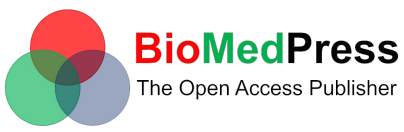

\begin{abstract}
Background: It has been revealed that herbal medicines have a palliative effect on pain. In the present study, the hypoalgesic effect of Spirulina platensis (microalgae) on the neuropathic pain induced by chronic constriction injury (CCl) was investigated. Methods: In the present study, 74 adult male Wistar rats weighing 200-220 grams were used. For inducing neuropathic pain, CCI was performed on the left sciatic nerve. Spirulina platensis was intragastrically administered daily for 3 weeks. Mechanical allodynia and thermal hyperalgesia were assessed by Von Frey hairs and plantar test device, respectively. Malondialdehyde (MDA) and total antioxidant capacity (TOC) were detected in the serum using thiobarbituric acid and ferric reducing ability of plasma (FRAP), respectively. Results: $\mathrm{CCl}$ of the sciatic nerve led to mechanical allodynia and thermal hyperalgesia at three weeks as well as two weeks post surgery. Three weeks of Spirulina therapy significantly $(P<0.05)$ decreased paw withdrawal response to mechanical and thermal stimulations, compared to control. FRAP, but not MDA, significantly decreased three weeks after CCl, and Spirulina therapy significantly reversed its level towards control. Conclusion: Chronic intragastric administration of Spirulina platensis alleviates CCl-induced neuropathic pain by modulating oxidative stress through increasing FRAP levels in male rats.
\end{abstract}

Key words: Chronic constriction injury, Neuropathic pain, Oxidative stress, Rat, Spirulina platensis

\section{INTRODUCTION}

Neuropathic pain is one of the major chronic health problems, with allodynia and hyperalgesia being the most common signals of pain ${ }^{1}$. Failure in response to standard treatments is a serious challenge in treating these conditions ${ }^{2,3}$. There are different etiologies for neuropathic pain but one of the most common causes is diabetic neuropathy; in fact, $50-60 \%$ of diabetic patients have polyneuropathy ${ }^{4}$. Several complicated and similar mechanisms have been associated with peripheral and central neuropathic pain. These mechanisms include increased release of excitatory neurotransmitters, modulation of descending inhibitory pathways, inflammatory reactions and oxidative stress $^{5-7}$, all of which may change with time thereby increasing complications ${ }^{8}$. With regard to these complications, all of the approaches presented above have not shown sufficient evidence of effective neuropathic pain treatment ${ }^{3,9}$. Furthermore, it should be noted that in addition to the varied side effects, standard pharmacologic medications also have serious interactions with each other, which must be considered. Therefore, alternative methods of suppressing and treating neuropathic pain are necessary. Plants have many valuable constituents that enable them to improve cellular function in healthy and diseased states. Plants and medicinal herbs have been used for a long time ago throughout the world for promoting health and as therapeutic agents in various disorders, such as cancer ${ }^{10}$, neuropathy ${ }^{11,12}$, and Parkinson's disease ${ }^{13}$. Among plants, Spirulina platensis is a marine microalgae which belongs to the class of cyanobacteria ${ }^{14}$, known for containing rich resources of carotenoids, trace elements, and vitamins ${ }^{15}$. Spirulina has many positive biological features, including anti-inflammatory and antioxidant $^{16,17}$, antimicrobial ${ }^{18}$, antitumoral ${ }^{19}$ and immunomodulatory properties. It was reported that Spirulina alleviates proinflammatory cytokine TNFalpha in the brain tissues of aged rats ${ }^{17}$. The antioxidant property of Spirulina is ascribed to its Cphycocyanin component ${ }^{20,21}$, which is a potent antioxidant.

There are several animal studies demonstrating the protective effects of Spirulina against environmental chemotoxicity and pharmacologic-induced oxidative stress ${ }^{22}$. For example, it has been reported that Spirulina reduces neuronal injury due to oxidative stress and ischemia ${ }^{23,24}$. It has also been reported that Spirulina protects different organs against toxicity of heavy metals and pharmacologic agents ${ }^{25-27}$. Indeed, 
Spirulina completely blocked MPTP (1-methyl-4phenyl-1, 2, 3, 6- tetrahydropyridine)-induced oxidative stress, partially reduced MPTP-induced Parkinson's disease symptoms in mice, and improved nigrostriatal dopamine pathway injury (caused by 6hydroxydopamine (6-OHDA)) in rats ${ }^{23,28}$. In light of these effects, it seems that the protective effects of Spirulina are, at least, due to its antioxidant properties, although other mechanisms may also play a role. Given the aforementioned impact of the role of oxidative stress and inflammation in peripheral neuropathic pain ${ }^{6}$, and the antioxidative properties of Spirulina microalgae, the aim of this study was to evaluate whether orally administered Spirulina could suppress neuropathic pain induced by chronic constriction injury (CCI) in rats. To our understanding, no other study has examined the effects of Spirulina therapy on CCI-induced neuropathic pain thus far.

\section{METHODS}

\section{Animals}

In this study, adult male Wistar rats weighing 200-220 grams were used. Animals were obtained from the animal house of Semnan University of Medical Sciences. The rats were kept in an environment where humidity, temperature, and light-dark cycle were controlled. Food and water were sufficiently available to the animals. All experimental procedures were performed, as approved by the local ethical committees on animal research of the Semnan University of Medical Sciences, under permit number 1394.217.

\section{Drug}

Spirulina platensis microalgae were provided from Qeshm Microalgae Biorefinery Company (Qeshm Island, Iran). Spirulina was in a powder form.Spirulina was dissolved in physiologic saline at concentrations of 200,400 , and $800 \mathrm{mg} / \mathrm{kg}$ and was administered intragastrically to the rats in a volume of $2 \mathrm{ml}$ by a gavage tube. The dosage of Spirulina platensis evaluated in our study were: $0,200,400$, and $800 \mathrm{mg} / \mathrm{kg}$.

\section{Induction of neuropathy}

Induction of neuropathy was performed through the method described by Bennett and Xie ${ }^{29}$. Animals were anesthetized using intraperitoneal injection of ketamine $(80 \mathrm{mg} / \mathrm{kg})$ and xylazine $(10 \mathrm{mg} / \mathrm{kg}) \mathrm{mix}$ ture. Using a surgical blade, a $2-\mathrm{cm}$ incision was made on the left thigh and the sciatic nerve was exposed and then released from the surrounding tissues. Using catgut chromic sutures 4-0,4 loose ligations were made around the common sciatic nerve at 1-mm intervals. At the end, the incisures sites (muscle and skin) were separately sutured with silk 4-0. In the sham group, after exposing the sciatic nerve only, muscle and skin were sutured.

\section{Experimental protocol and groups}

In this study, 74 male rats were used in two experiments. In the first experiment, 37 rats were randomly assigned to 6 groups (Intact, Sham, Neuropathy, Neuropathy with Spirulina $(200 \mathrm{mg} / \mathrm{kg})$, Neuropathy with Spirulina (400 mg/kg), and Neuropathy with Spirulina $(800 \mathrm{mg} / \mathrm{kg}))$ for behavioral and oxidative stress tests at 14 days post surgery. In the second experiment, another 37 rats were assigned to the same groups and tested at 21 days post surgery. Saline or Spirulina gavages were initiated on the post surgery day and continued on to 14 and 21 days after surgery in the first and second experiments, respectively. Spirulina was dissolved in physiologic saline and was intragastrically administered in a volume of $2 \mathrm{ml}$ by a gavage tube. Four rats were paralyzed and thus excluded from the study. The study design is demonstrated in Table 1.

\section{Assessment of pain behavior of the animals}

Pain response was evaluated using the following tests:

\section{Mechanical allodynia}

Paw withdrawal response was detected using the von Frey's hairs (Stoelting, Wood Dale, IL, and USA) which were described by Ren et al. ${ }^{30}$. Von Frey's hairs are calibrated filaments that, depending on their thickness, apply a certain force (in grams) to the surface to which they are pressed. The filaments were applied with ascending style on the dorsal surface of the injured hind paws. The experiment began with a low force and if there was no response, a greater force was applied. If the animal withdrew its foot three times per five stimuli delivered, that force was considered as a response. A stimulus equivalent to $60 \mathrm{~g}$ was considered as the cut-off force.

\section{Thermal hyperalgesia}

The animals were placed in the plantar test device and after habituation, infrared radiation was applied to the plantar surface of the injured paw with an intensity of sixty. Infrared radiation was displayed every five minutes in three rounds. Withdrawal latency to each thermal stimulus was recorded and the average of three rounds was considered as response. Sixty seconds was set as cut-off point of the test ${ }^{29}$. 
Table 1: Design of the study

\begin{tabular}{clll}
\hline Groups & Surgery & Gavages & Behavioral, oxidative stress tests \\
Experiment 1 & Day 0 & Days 1-13 & Day 14 \\
Experiment 2 & Day 0 & Days 1-20 & Day 21 \\
\hline
\end{tabular}

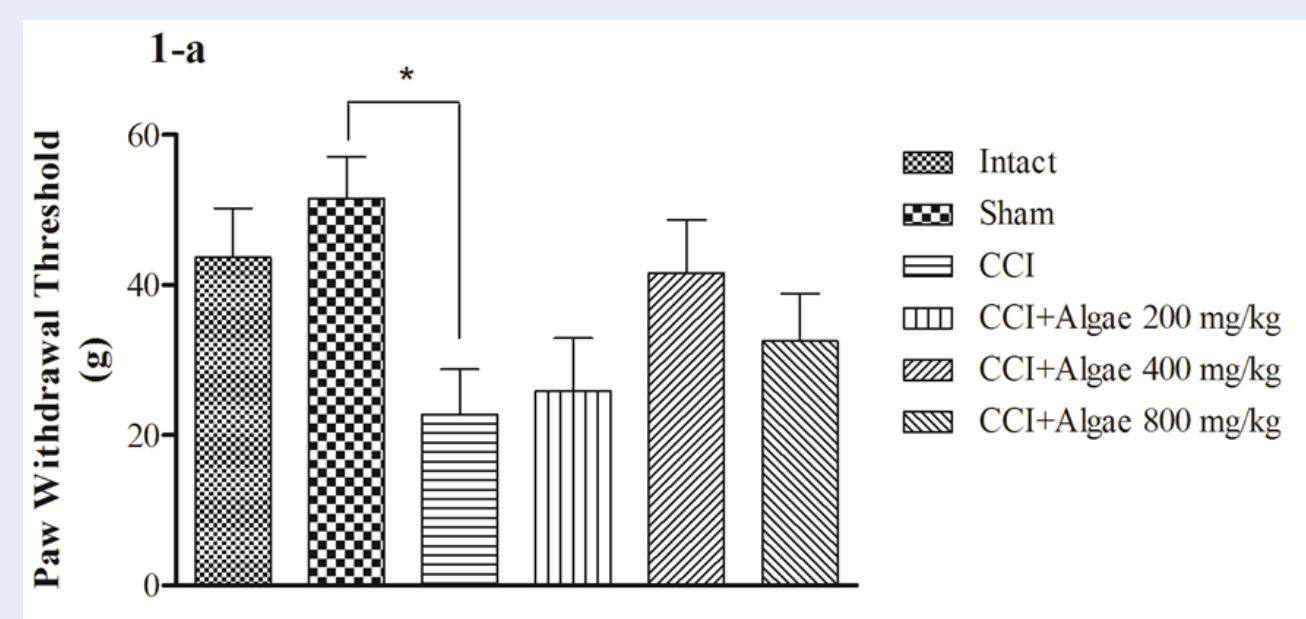

\section{1-b}

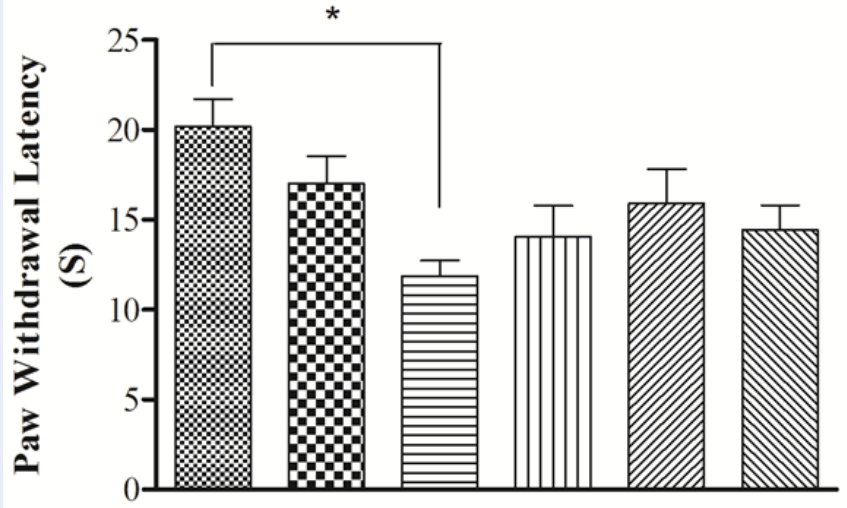

Intact

Sham

ЕCCI

एा CCI+Algae $200 \mathrm{mg} / \mathrm{kg}$

27It CCI+Algae $400 \mathrm{mg} / \mathrm{kg}$

लाख CCI+Algae $800 \mathrm{mg} / \mathrm{kg}$

Figure 1: Effect of Spirulina Platensis microalgae on the chronic constriction injury-induced neuropathic pain at 14 days post lesion in male rats. Chronic constriction injury of sciatic nerve led to significant tactile allodynia (A) and thermal hyperalgesia (B). Administration of Spirulina did not change mechanical allodynia and thermal hyperalgesia at 2 weeks post injury. All data are expressed as mean \pm S.E.M of measured variable. $\mathrm{N}=7-9$. ${ }^{*} P<0.05$

\section{Assessment of oxidative stress reaction}

Oxidative stress was evaluated using malondialdehyde (MDA) and ferric reducing ability of plasma (FRAP) assay of the rats' blood.

\section{Blood sampling}

Blood samples were prepared from the rats' hearts while they were anesthetized. Using a centrifuge with
$2000 \mathrm{rpm}$ for $10 \mathrm{~min}$, the serum was removed from the blood and kept at $-80^{\circ} \mathrm{C}$ until use in the MDA and FRAP assays.

\section{MDA assay}

The MDA was assayed in rat serum. Thiobarbituric acid method was used to measure lipid peroxidation $^{31}$. Peroxidation of unsaturated fatty acids increases through oxidative stress, and various alde- 

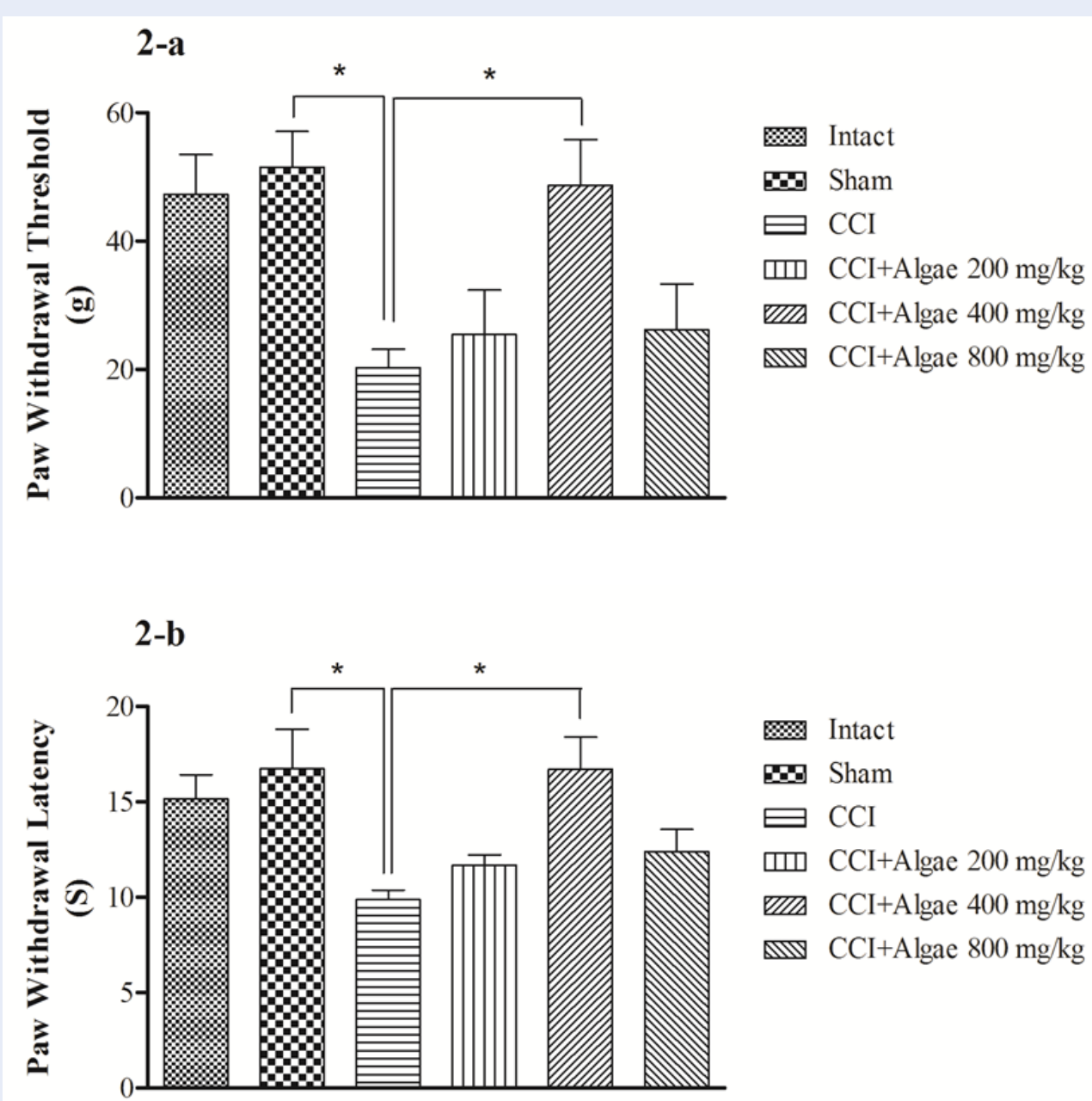

Intact

00 Sham

C $\mathrm{CCI}$

एس) CCI+Algae $200 \mathrm{mg} / \mathrm{kg}$

שII CCI+Algae $400 \mathrm{mg} / \mathrm{kg}$

CIV $\mathrm{CCI}+\mathrm{Algae} 800 \mathrm{mg} / \mathrm{kg}$

Figure 2: Effect of Spirulina Platensis microalgae on the chronic constriction injury-induced neuropathic pain at 21 days post lesion in male rats. Paw withdrawal threshold for mechanical and thermal stimulation significantly decreased compared to control groups. Spirulina significantly reduced both of tactile response $(P<0.05)(\mathbf{A})$ and thermal response $(\mathrm{P}<0.05)(\mathbf{B})$ at 3 weeks post-CCI. All data are expressed as mean \pm S.E.M of measured variable. $\mathrm{N}=6-9 .{ }^{*} \mathrm{P}<0.05$

hydes (including MDA) are produced. MDA (as a marker of oxidative stress) reacts with thiobarbituric acid in acidic regions at high temperatures. The maximum absorption was evaluated at $535 \mathrm{~nm}$ using a spectrophotometer.

\section{FRAP assay}

For detecting FRAP, measurement of total antioxidant capacity (TAC) in the rat serum was used. The ability of the serum to reduce $\mathrm{Fe}^{3+}$ ions to $\mathrm{Fe}^{2+}$ is the basis of this method and the output is a blue complex solution which shows the maximum light absorption at $593 \mathrm{~nm}$ wavelength ${ }^{32}$.

\section{Statistical analysis}

One-way analysis of variance (ANOVA) and Tukey's post-hoc test were used for analyzing the data. All data were expressed as mean \pm SEM of the detected variables; $\mathrm{P}<0.05$ was considered significant.

\section{RESULTS}

Our results revealed that Spirulina can suppress neuropathic pain induced by CCI. The results were divided in two parts- behavioral and biochemical.

\section{Behavioral results}

We evaluate the effects of Spirulina platensis on neuropathic pain in rats. We found that Spirulina therapy 


\section{3-a}

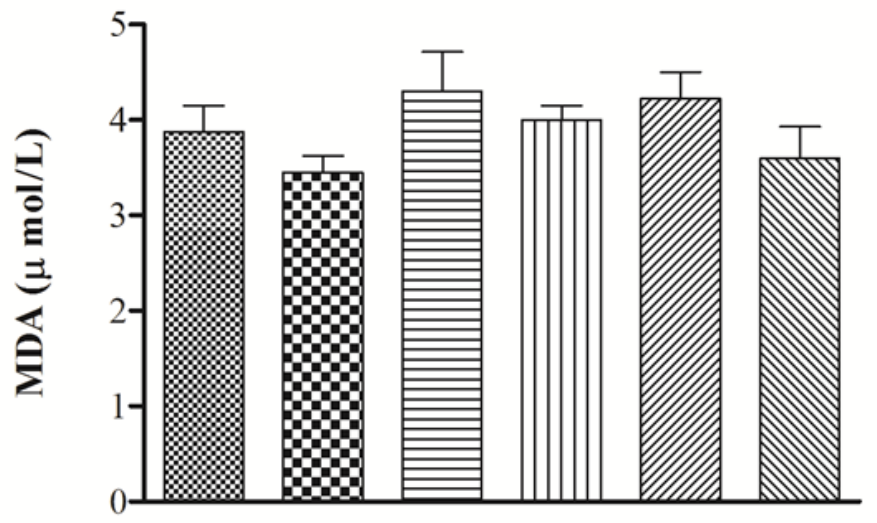

Intact

E.rog Sham

ए CCI

एس Algae $200 \mathrm{mg} / \mathrm{kg}$

שIA Algae $400 \mathrm{mg} / \mathrm{kg}$

Algae $800 \mathrm{mg} / \mathrm{kg}$

\section{3-b}

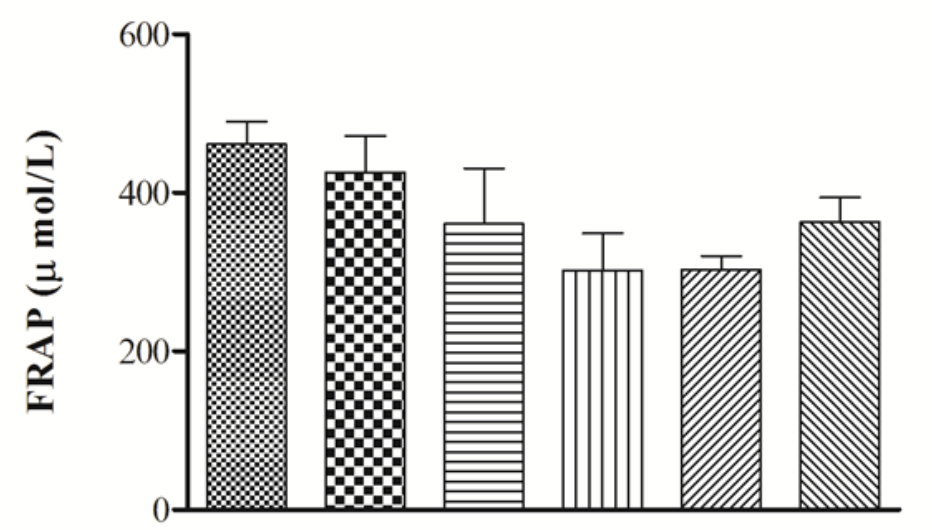

Intact

표 Sham

$\mathrm{CCI}$

एण Algae $200 \mathrm{mg} / \mathrm{kg}$

שIA Algae $400 \mathrm{mg} / \mathrm{kg}$

लW Algae $800 \mathrm{mg} / \mathrm{kg}$

Figure 3: Effect of Spirulina Platensis microalgae on the serum MDA and FRAP level in male rats at days fourteen post-CCI. Level of MDA and FRAP in the $\mathrm{CCl}$ groups did not show significant difference against that in the control groups. 2 weeks spirulina therapy following $\mathrm{CCI}$ did not change MDA level $(\mathbf{A})$ and the level of FRAP (B) compared to $\mathrm{CCl}$ group. All data are expressed as mean \pm S.E.M of measured variable. $\mathrm{N}=4-9$.

significantly reversed CCI-induced neuropathic pain, relative to control group, after 21 days of treatment.

From experiment 1, mechanical allodynia and thermal hyperalgesia were significantly reduced in CCI groups compared to intact and sham groups, respectively (Figure 1A, B). However, neuropathic pain was not improved by Spirulina therapy. Paw withdrawal responses (mechanical and thermal) were not significantly different in the treatment groups, compared to CCI group, at 14 days post CCI (Figure 1A, B).

In Experiment 2, mechanical allodynia and thermal hyperalgesia were significantly reduced in CCI groups, compared to control/sham groups (Figure 2A, B). Spirulina significantly improved neuropathic pain at 21 days post therapy. Our results showed that Spirulina therapy significantly decreased mechanical allodynia $[\mathrm{P}<0.05, \mathrm{~F}(5,38)$ $=5.07]$ and thermal hyperalgesia $[\mathrm{P}<0.05, \mathrm{~F}(5,34)$ $=4.45]$, compared to CCI group (Figure 2A, B). The pain reducing effect of Spirulina was observed with moderate dose $(400 \mathrm{mg} / \mathrm{kg})$, as tested in the present study. The effect of Spirulina on pain behavior showed an inverse $U$ pattern such that a reducing effect on neuropathic pain was observed with a dose of $400 \mathrm{mg} / \mathrm{kg}$ but not with $200 \mathrm{or} 800 \mathrm{mg} / \mathrm{kg}$. 


\section{4-a}
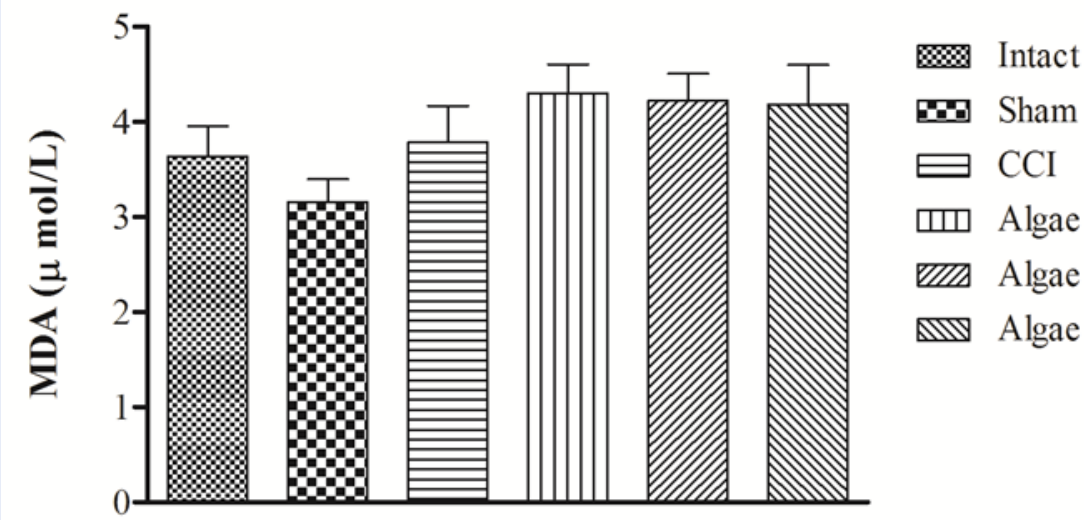

एण Algae $200 \mathrm{mg} / \mathrm{kg}$

שIIS Algae $400 \mathrm{mg} / \mathrm{kg}$

Мा Algae $800 \mathrm{mg} / \mathrm{kg}$

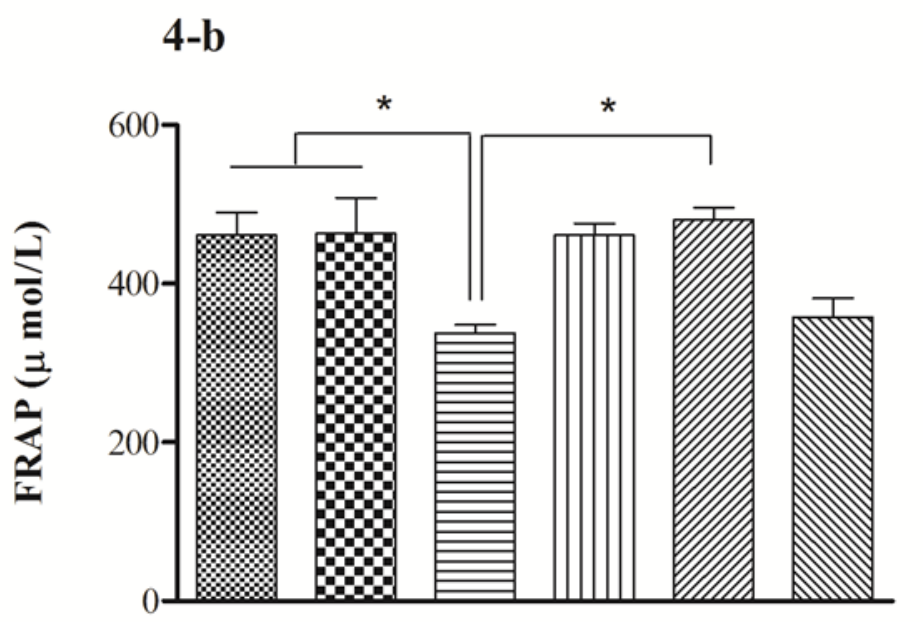

$\otimes$ Intact

표묘 Sham

Е CCI

एा Algae $200 \mathrm{mg} / \mathrm{kg}$

שIIA Algae $400 \mathrm{mg} / \mathrm{kg}$

М. Algae $800 \mathrm{mg} / \mathrm{kg}$

Figure 4: Effect of Spirulina Platensis microalgae on the serum MDA and FRAP level in male rats. MDA Level at 21 days did not show significant difference in the $\mathrm{CCl}$ group against that in the control group (A). However, level of FRAP at post-CCl day 21 significantly reduced compared to intact and sham groups. 3 weeks Spirulina therapy (dose of $400 \mathrm{mg} / \mathrm{kg}$ ) significantly increased FRAP level compared to CCl group (B). All data are expressed as mean \pm S.E.M of measured variable. $\mathrm{N}=4-9$. ${ }^{*} P<0.05$

\section{Oxidative stress results}

Using MDA and FRAP as oxidative markers, we studied the oxidative stress alteration during Spirulina therapy in a CCI-induced neuropathic pain situation. In both experiments, the MDA level was not significantly different between the groups (Figure 3A and Figure 4A). Like MDA levels, FRAP levels in Experiment 1 was not significantly different between that of the control, CCI, or treatment groups (Figure 3B). On the other hand, FRAP was significantly reduced compared to intact and sham groups in experiment 2 (Figure 4B). Treatment with Spirulina $(400 \mathrm{mg} / \mathrm{kg}$ ) led to a significant increase $[\mathrm{P}<0.05, \mathrm{~F}(5,33)=4.5]$ of FRAP levels at 21 days post CCI. However, FRAP measurement did not show improvement at 14 days post CCI.

\section{DISCUSSION}

Neuropathic pain is a severe debilitating problem following somatosensory injury. Several reports have revealed the efficacy of medicinal herbs in treating neuropathic pain ${ }^{33-35}$. In the present study, we evaluated the efficiency of Spirulina platensis microalgae on alleviating neuropathic pain induced by CCI of sciatic nerve in male rats. To our knowledge, this is the first study to study the effects of Spirulina platensis on sciatic neuropathic pain treatment. 


\section{Hypoalgesic effects}

Our results revealed that CCI leads to mechanical allodynia and thermal hyperalgesia, consistent with findings from our previous study ${ }^{6}$. Spirulina microalgae significantly reduced CCI-induced neuropathic pain. Intragastric administration of Spirulina powder significantly increased paw withdrawal threshold and paw withdrawal latency in neuropathic animals at 21 days after induction of neuropathy (Figure 2). Nisha Patro et al. reported that oral use of Spirulina alleviates arthritis pain through suppressing inflammatory processes and microglial activation in the spinal cord $^{36}$. Previously, we reported that inflammatory mediator release due to CCI is one of the main mechanisms leading to neuropathic pain ${ }^{6}$. Consistent with the studies which suggest an anti inflammatory property for Spirulina and its content Cphycocyanin ${ }^{17,37,38}$, it is possible that in the present study Spirulina led to analgesia through suppressing inflammatory mediators. In the present study, the hypoalgesic effect of Spirulina was observed when using a moderate dose of Spirulina (400 mg/kg). Consistent with our results, Patro et al. showed that a dose of 400 $\mathrm{mg} / \mathrm{kg}$ was effective in their behavioral (sciatic function index) and molecular (downregulation of IbA1 as an index of microglial activation at both of ventral and dorsal horns of the spinal cord) experiments compared to higher doses ${ }^{36}$. In the present study, the doses of 200 and $800 \mathrm{mg} / \mathrm{kg}$ did not show any positive effect on reducing neuropathic pain. Spirulina administration showed an inverse $U$ effect on behavioral tests.

\section{Antioxidant effects}

The results of this study showed that the antioxidant properties of phytochemicals alleviate neuropathic pain. Our results showed that Spirulina has an antioxidant capacity. We investigated the antioxidant activity of Spirulina by performing FRAP and MDA assays on the serum of chronic constriction injured rats.

In our study, MDA as an oxidative stress marker did not change between control and treatment groups. Several in vitro and in vivo studies revealed the antioxidant properties of Spirulina through decrease of MDA levels ${ }^{6,27,39}$. However, the present results are consistent with our previous results ${ }^{6}$; MDA levels were not significantly different between the control and neuropathy groups. It is may be that in the present model, changes in the MDA levels makes longer period of time. However, more research on this topic needs to be undertaken. Another possible explanation for this observation is that other antioxidant biomarkers may have changed.

Our results revealed that FRAP levels were significantly reduced in neuropathic rats but prominently increased following Spirulina therapy (Figure 4). It has been reported that pre-treatment with Spirulina reduces motor disturbances following spinal cord injury in rats ${ }^{40}$. Moreover, it was reported that Spirulina improves nigrostriatal system injury in the rats ${ }^{28}$. Consistent with our results, there have been several reports about the role of Spirulina in the increasing the level of TOC. It has been shown that drug and chemical-induced histopathological damages were alleviated by Spirulina therapy in rats ${ }^{22,26}$. Khan and his colleagues, in 2005, showed that Spirulina has a protective effect on doxorubicin-induced damage to heart through normalizing antioxidant enzymes ${ }^{41}$. Thaakur et al. showed that vascular ischemic injury was suppressed by Spirulina and that this effect seemed to be due to the antioxidant activity of Spirulina $^{24}$

In addition to animal studies, the efficacy of Spirulina as an antioxidant has been demonstrated in clinical studies. Orally administered Spirulina (daily dose of $8 \mathrm{~g}$ for 4 weeks) led to a significant increase of TOC, which occurred in parallel to prolongation of fatigue during physical activity in male human subjects ${ }^{42}$. Spirulina is a rich source of Cphycocyanin $^{22,43}$. In fact, various studies have reported that C-phycocyanin has an antioxidative ability ${ }^{44,45}$. It was reported that orally administration of C-phycocyanin protected the rat hippocampus neurons against kainic acid-induced injury through antioxidant activity ${ }^{46}$. Romay et al., in 1998, showed the ability of phycocyanin in scavenging hydroxyl and alkoxyl radicals ${ }^{47}$. It has been reported that the antioxidant activity of phycocyanin provides anti-inflammatory effects in animal models, such as arachidonic acid-induced ear edema in mice and carageenan-induced paw edema in rats ${ }^{38}$.

Considering the reports mentioned above, it seems that the suppressive effect of Spirulina on CCIinduced neuropathic pain is due to its antioxidant ability through enhancement of plasma TOC or through inhibiting inflammatory processes. In the future, it is important to evaluate in further detail the inflammatory mediators, such as TNF-alpha, and antioxidant biomarkers, such as superoxide dismutase and glutathione. This was one of the limitations of the present study; i.e. we did not evaluate additional mediators and biomarkers due to expenses. 


\section{CONCLUSION}

The most obvious finding to emerge from this study is that Spirulina microalgae can reduce neuropathic pain induced by chronic constriction injury in male rats. This effect is caused by the antioxidant activity of Spirulina through increasing FRAP levels.

\section{COMPETING INTERESTS}

All authors have nothing to disclose and have no financial or commercial conflict of interests in the present study.

\section{AUTHORS' CONTRIBUTIONS}

Dr. Ghanbari and Mr Safakhah carried out the design and coordinated the study, participated in most of the experiments. Dr. Bandegi, Mr Moradi kor and Miss Tamimi carried out all the experiments. Dr. Ghanbari, Dr Bandegi and Mr Safakhah carried out the Analysis of data. Dr. Ghanbari, Mr Safakhah and Miss Tamimi participated in manuscript preparation. All authors have read and approved the content of the manuscript.

\section{ACKNOWLEDGMENTS}

Research reported in the present publication was supported by a grant (number 1394.217) from Semnan University of Medical Sciences, and the authors announce their appreciation.

\section{ETHICS APPROVAL AND CONSENT TO PARTICIPATE}

Ethics approval for this study was obtained from the Institutional Review Board of Semnan University of Medical Sciences, in order to the Helsinki declaration (No 1394; 217)

\section{AVAILABILITY OF DATA AND MATERIALS}

Authors will provide if requested.

\section{FUNDING}

Semnan University of Medical Sciences, Semnan, Iran.

\section{REFERENCES}

1. Ueda H. Molecular mechanisms of neuropathic painphenotypic switch and initiation mechanisms. Pharmacology \& Therapeutics. 2006;109:57-77. Available from: DOI: 10.1016/j.pharmthera.2005.06.003.

2. Attal N, Cruccu G, Baron R, Haanpää M, Hansson P, Jensen TS, et al. EFNS guidelines on the pharmacological treatment of neuropathic pain: 2010 revision. European Journal of Neurology. 2010;17:1113-e88. Available from: DOI:10.1111/j.14681331.2010.02999.x.
3. Dworkin RH, Backonja M, Rowbotham MC, Allen RR, Argoff CR, Bennett GJ. Advances in neuropathic pain: diagnosis, mechanisms, and treatment recommendations. Archives of Neurology. 2003;60:1524-34. Available from: DOI:10.1001/archneur. 60.11 .1524 .

4. Nickel FT, Seifert F, Lanz S, Maihöfner C. Mechanisms of neuropathic pain. European Neuropsychopharmacology. 2012;22:81-91. Available from: DOI:10.1016/j.euroneuro. 2011.05.005.

5. Campbell JN, Meyer RA. Mechanisms of neuropathic pain Neuron. 2006;52:77-92. Available from: DOI:10.1016/j. neuron.2006.09.021.

6. Safakhah HA, Kor NM, Bazargani A, Bandegi AR, Pourbadie HG, Khoshkholgh-Sima B. Forced exercise attenuates neuropathic pain in chronic constriction injury of male rat: an investigation of oxidative stress and inflammation. Journal of Pain Research. 2017;10:1457-66. Available from: Doi:10.2147/jpr.s135081.

7. Basbaum Al. Distinct neurochemical features of acute and persistent pain. Proceedings of the National Academy of Sciences of the United States of America. 1999:96:7739-43. Available from: DOI:10.1073/pnas.96.14.7739.

8. Woolf CJ, Mannion RJ. Neuropathic pain: aetiology, symptoms, mechanisms, and management. Lancet. 1999;353:1959-64. Available from: Doi:10.1016/s01406736(99)01307-0.

9. Suzuki Y, Mitsuhata H, Yuzurihara M, Kase Y. Antiallodynic effect of herbal medicine yokukansan on peripheral neuropathy in rats with chronic constriction injury. Evidence-Based Complementary and Alternative Medicine. 2012;2012:953459. Available from: Doi:10.1155/2012/953459.

10. Cragg GM, Newman DJ. Plants as a source of anti-cancer agents. Journal of Ethnopharmacology. 2005;100:72-9. Available from: DOI:10.1016/j.jep.2005.05.011.

11. Muthuraman A, Singh N. Attenuating effect of Acorus calamus extract in chronic constriction injury induced neuropathic pain in rats: an evidence of anti-oxidative, anti-inflammatory, neuroprotective and calcium inhibitory effects. BMC Complementary and Alternative Medicine. 2011;11:24. Available from: Doi:10.1186/1472-6882-11-24.

12. Garg G, Adams JD. Treatment of neuropathic pain with plant medicines. Chinese Journal of Integrative Medicine. 2012;18:565-70. Available from: DOI:10.1007/s11655-0121188-6.

13. Kampen JV, Robertson $\mathrm{H}$, Hagg T, Drobitch R. Neuroprotective actions of the ginseng extract G115 in two rodent models of Parkinson's disease. Experimental Neurology. 2003;184:5219. Available from: DOI:10.1016/j.expneurol.2003.08.002.

14. Sapp J. The prokaryote-eukaryote dichotomy: meanings and mythology. Microbiology and Molecular Biology Reviews. 2005;69:292-305. Available from: Doi:10.1128/mmbr.69.2. 292-305.2005.

15. Mazo VK, Gmoshinskiĭ IV, Zilova IS. [Microalgae Spirulina in human nutrition]. Voprosy Pitaniia. 2004;73:45-53.

16. Dartsch PC. Antioxidant potential of selected Spirulina platensis preparations. Phytotherapy Research. 2008;22:627-33. Available from: DOI:10.1002/ptr.2310.

17. Gemma C, Mesches MH, Sepesi B, Choo K, Holmes DB, Bickford PC. Diets enriched in foods with high antioxidant activity reverse age-induced decreases in cerebellar beta-adrenergic function and increases in proinflammatory cytokines. The Journal of Neuroscience : The Official Journal of the Society for Neuroscience. 2002;22:6114-20. Available from: Doi: 10.1523/jneurosci.22-14-06114.2002.

18. Borowitzka MA. Micro-algae as sources of fine chemicals. Microbiological Sciences. 1986;3:372-5.

19. Negishi T, Rai $H$, Hayatsu $H$. Antigenotoxic activity of natural chlorophylls. Mutation Research. 1997;376:97-100. Available from: Doi:10.1016/s0027-5107(97)00030-4.

20. Estrada JEP, Bescós PB, del Fresno AMV. Antioxidant activity of different fractions of Spirulina platensis protean extract. II Farmaco. 2001;56:497-500. Available from: Doi:10.1016/s0014$827 \times(01) 01084-9$. 
21. Bhat VB, Madyastha KM. C-phycocyanin: a potent peroxyl radical scavenger in vivo and in vitro. Biochemical and Biophysical Research Communications. 2000;275:20-5. Available from: DOI:10.1006/bbrc.2000.3270.

22. Deng R, Chow TJ. Hypolipidemic, antioxidant, and antiinflammatory activities of microalgae Spirulina. Cardiovascular Therapeutics. 2010;28:e33-45. Available from: DOI:10.1111/j. 1755-5922.2010.00200.x.

23. Chamorro G, Pérez-Albiter M, Serrano-García N, MaresSámano JJ, Rojas P. Spirulina maxima pretreatment partially protects against 1-methyl-4-phenyl1,2,3,6-tetrahydropyridine neurotoxicity. Nutritional Neuroscience. 2006;9:207-12. Available from: Doi:10.1080/10284150600929748.

24. Thaakur S, Sravanthi R. Neuroprotective effect of Spirulina in cerebral ischemia-reperfusion injury in rats. Journal of Neural Transmission (Vienna, Austria). 2010;117:1083-91. Available from: DOI:10.1007/s00702-010-0440-5.

25. Karadeniz A, Yildirim A, Simsek N, Kalkan Y, Celebi F. Spirulina platensis protects against gentamicin-induced nephrotoxicity in rats. Phytotherapy Research. 2008;22:1506-10. Available from: DOI:10.1002/ptr.2522.

26. Karadeniz A, Cemek M, Simsek N. The effects of Panax ginseng and Spirulina platensis on hepatotoxicity induced by cadmium in rats. Ecotoxicology and Environmental Safety. 2009;72:231-5. Available from: DOI:10.1016/j.ecoenv.2008.02. 021.

27. Khan M, Shobha JC, Mohan IK, Naidu MUR, Prayag A, Kutala VK. Spirulina attenuates cyclosporine-induced nephrotoxicity in rats. Journal of Applied Toxicology. 2006;26:444-51. Available from: DOI:10.1002/jat.1159.

28. Strömberg I, Gemma C, Vila J, Bickford PC. Blueberry- and spirulina-enriched diets enhance striatal dopamine recovery and induce a rapid, transient microglia activation after injury of the rat nigrostriatal dopamine system. Experimental Neurology. 2005;196:298-307. Available from: DOI:10.1016/j. expneurol.2005.08.013.

29. Bennett GJ, Xie YK. A peripheral mononeuropathy in rat that produces disorders of pain sensation like those seen in man. Pain. 1988;33:87-107. Available from: Doi:10.1016/03043959(88)90209-6.

30. Ren K. An improved method for assessing mechanical allodynia in the rat. Physiology \& Behavior. 1999;67:711-6. Available from: Doi:10.1016/s0031-9384(99)00136-5.

31. Mihara M, Uchiyama M. Determination of malonaldehyde precursor in tissues by thiobarbituric acid test. Analytical Biochemistry. 1978;86:271-8. Available from: Doi:10.1016/00032697(78)90342-1.

32. Benzie IF, Strain JJ. The ferric reducing ability of plasma (FRAP) as a measure of "antioxidant power": the FRAP assay. Analytical Biochemistry. 1996;239:70-6. Available from: DOI: 10.1006/abio.1996.0292.

33. Comelli F, Giagnoni G, Bettoni I, Colleoni M, Costa B. Antihyperalgesic effect of a Cannabis sativa extract in a rat model of neuropathic pain: mechanisms involved. Phytotherapy Research. 2008;22:1017-24. Available from: DOI:10.1002/ptr. 2401.

34. Kanter M. Effects of Nigella sativa and its major constituent, thymoquinone on sciatic nerves in experimental diabetic neuropathy. Neurochemical Research. 2008;33:87-96. Available from: DOI:10.1007/s11064-007-9419-5.
35. Kim YS, Park HJ, Kim TK, Moon DE, Lee HJ. The effects of Ginkgo biloba extract EGb 761 on mechanical and cold allodynia in a rat model of neuropathic pain. Anesthesia and Analgesia. 2009;108:1958-63. Available from: DOI:10.1213/ane. 0b013e31819f1972.

36. Patro N, Sharma A, Kariaya K, Patro I. Spirulina platensis protects neurons via suppression of glial activation and peripheral sensitization leading to restoration of motor function in collagen-induced arthritic rats. Indian Journal of Experimental Biology. 2011;49:739-48.

37. Somchit MN, Mohamed NA, Ahmad Z, Zakaria ZA, Shamsuddin L, Omar-Fauzee MS. Anti-inflammatory and anti-pyretic properties of Spirulina platensis and Spirulina lonar: a comparative study. Pakistan Journal of Pharmaceutical Sciences. 2014;27:1277-80.

38. Romay C, Ledón N, González R. Further studies on antiinflammatory activity of phycocyanin in some animal models of inflammation. Inflammation Research. 1998;47:334-8. Available from: DOI:10.1007/s000110050338.

39. Ray S, Roy K, Sengupta C. In vitro evaluation of protective ef fects of ascorbic acid and water extract of Spirulina plantesis (blue green algae) on 5-fluorouracil-induced lipid peroxidation. Acta Poloniae Pharmaceutica. 2007;64:335-44.

40. Aziz I, Ramli MDC, Zain NSM, Sanusi J. Behavioral and Histopathological Study of Changes in Spinal Cord Injured Rats Supplemented with Spirulina platensis. Evidence-Based Complementary and Alternative Medicine. 2014;2014:871657. Available from: Doi:10.1155/2014/871657.

41. Khan M, Shobha JC, Mohan IK, Naidu MU, Sundaram C, Singh S. Protective effect of Spirulina against doxorubicin-induced cardiotoxicity. Phytotherapy Research. 2005;19:1030-7. Available from: DOI:10.1002/ptr.1783.

42. Kalafati M, Jamurtas AZ, Nikolaidis MG, Paschalis V, Theodorou AA, Sakellariou GK. Ergogenic and antioxidant effects of spirulina supplementation in humans. Medicine and Science in Sports and Exercise. 2010;42:142-51. Available from: DOI: 10.1249/MSS.0b013e3181ac7a45.

43. Ahmad S, Israf DA, Lajis NH, Shaari $K$, Mohamed H, Wahab AA. Cardamonin, inhibits pro-inflammatory mediators in activated RAW 264.7 cells and whole blood. European Journal of Pharmacology. 2006;538:188-94. Available from: DOI: 10.1016/j.ejphar.2006.03.070.

44. Khan M, Varadharaj S, Shobha JC, Naidu MU, Parinandi NL, Kutala VK. C-phycocyanin ameliorates doxorubicin-induced oxidative stress and apoptosis in adult rat cardiomyocytes. Journal of Cardiovascular Pharmacology. 2006;47:9-20. Available from: DOI:10.1097/01.fjc.0000191520.48404.27.

45. Riss J, Décordé K, Sutra T, Delage M, Baccou JC, Jouy N. Phycobiliprotein C-phycocyanin from Spirulina platensis is powerfully responsible for reducing oxidative stress and NADPH oxidase expression induced by an atherogenic diet in hamsters. Journal of Agricultural and Food Chemistry. 2007;55:7962-7. Available from: DOI:10.1021/jf070529g.

46. Rimbau V, Camins A, Romay C, González R, Pallàs M. Protective effects of $C$-phycocyanin against kainic acid-induced neuronal damage in rat hippocampus. Neuroscience Letters. 1999;276:75-8. Available from: Doi:10.1016/s0304-3940(99) 00792-2.

47. Romay C, Armesto J, Remirez D, González R, Ledon N, García I. Antioxidant and anti-inflammatory properties of Cphycocyanin from blue-green algae. Inflammation Research. 1998;47:36-41. Available from: DOI:10.1007/s000110050256.

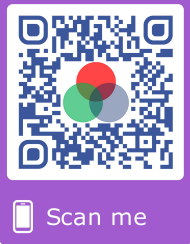

